\title{
Establishment and characterization of a cell line HCS1220 from human liver metastasis of colon cancer
}

Yi Chai ${ }^{1+}$, Huan Wang ${ }^{2 \dagger}$ and Fang Zhou ${ }^{2 *}$

\begin{abstract}
Background: To establish one primary cell line of human liver metastasis of colon cancer.

Methods: HCS1220 cell line was derived from one liver metastasis of colon cancer patient's resected tumor sample. The characterization of the cell line was defined by karyotype analysis, short tandem repeat (STR) analysis and mycoplasma contamination. Subcutaneous injection $1 \times 10^{6}$ cells to four BALB/c nude mice, the viable tumors were developed and diagnosed (H\&E staining). The expression of biomarkers CK20 and CDX2 for colon cancer were determined by immunocytochemistry assay.
\end{abstract}

Results: HCS1220 cell line can grow stably and continuously passage. During the grow process, the contact loss in the growth process and superimposed growth, which could be defined as proliferation of malignant tumor. Chromosome analysis revealed the cells derived from human female. The cells were not contaminated by mycoplasma. By immunohistochemistry, the cell line was proven to express the biomarkers of colon cancer CK20 and CDX2, while a-fetoprotein, hep-1 and glypican-3 were stained negative, which demonstrated that the HCS1220 cell line originating from the intestinal tissue.

Conclusions: HCS1220 cell line has the characteristics of primary human liver metastasis of colon cancer. The results of STR have genetically showed that cell line is original, which can provided cell materials for research in vitro and can also help for establishing the mechanism model of liver metastasis of colon cancer and preparing, screening and evaluating anti-tumor drugs.

Keywords: Colon cancer liver metastasis, Cell Line HCS1220, STR analysis, Karyotype analysis, Biomarkers

\section{Background}

Colon cancer is a common clinical malignant digestive system cancer and it is the third malignant in the world [1]. Like other solid tumors, the high mortality of colon cancer is also associated with high metastasis risk and the liver is the major organ [2]. Survey data show that about $15 \%$ to $25 \%$ of colon cancer patients may occur liver metastases, which is an essential cause of the poor prognosis of colon cancer [3]. Therefore, the control and

\footnotetext{
*Correspondence: zf1113@163.com

${ }^{\dagger}$ Yi Chai and Huan Wang contributed equally to this work

${ }^{2}$ Key Lab of Drug Metabolism and Pharmacokinetics, China

Pharmaceutical University, 24 Tong Jia Xiang, Nanjing, Jiangsu, China

Full list of author information is available at the end of the article
}

treatment of liver metastasis is the important method to improve the survival time with colon cancer.

Human primary tumor cell lines are extremely important for studying the pathogenesis of tumors and developing individual therapy. Currently, the tumor cell lines derived from the tumor tissue of patients have been widely used in drug screening and drug resistance research, tumor microenvironment, colon cancer pathogenesis and metastasis mechanism [4]. However, there is few cell line origined from human liver metastasis of colon cancer, just only about 10 human liver metastatic cell lines existing in ATCC, DSMZ, JCRB and RIKEN databases. Therefore, establishing more human liver metastasis of colon cancer cell line is important to tumor research. 
In this study, we described the characteristics of human liver metastasis of colon cancer cell line which named HCS1220, including the cell morphology in vitro and short tandem repeat genotyping (STR) $[5,6]$. The cell line was not contaminated by mycoplasma. By immunohistochemistry, HCS1220 was proven to express the biomarkers of colon cancer CK20 and CDX2. Subcutaneous injection $1 \times 10^{6}$ cells to four BALB/c nude mice, from the 3rd week, all tumors were formed and poorly differentiated adenocarcinoma in morphology confirmed by histopathological examination. Cytogenetic analysis showed multiple chromosomal aberrations, with a consistent deletion in the long arm and deletions or rearrangements in the short arm of chromosome.

\section{Methods}

\section{Patient}

The cell line was derived from a liver metastasis of colon cancer patient who was a 69-year-old woman in Jiangsu province hospital. 2014 the patient was carried out the surgery of colon cancer. In 2016 Dec, laboratory examination results showed CEA 64.4 ng/ml, CA199 24.4 U/ ml, CA724 $29.9 \mathrm{U} / \mathrm{ml}$, NSE 32.4 ng/ml; Colonoscopy biopsy showed Sigmoid adenocarcinoma. MRI examination demonstrated a space-occupying lesion in the right lobe. The resected liver tumor was approximately $5 \times 5 \times 2.5 \mathrm{~cm}$, pathological results showed hepatic adenocarcinoma, II-III stage.

\section{Establishment of the HCS1220 cell line}

A portion of tumor tissue ( $3 \mathrm{gm}$ ) resected from liver during the operation and immediately washed in DMEM medium. The tissue was cut $1 \mathrm{~mm}^{3}$ into tissue-culture flasks (Corning Glass Works, Corning, NY), washed twice with $1 \times \mathrm{PBS}\left(\mathrm{Ca}^{2+}, \mathrm{Mg}^{2+}\right.$ free $)$ and $1 \times$ Wash Medium (Invitrogen), After digestion using 0.1\% Collagenase Type IV (Gibco) in DMEM for $30 \mathrm{~min}$ at $37^{\circ} \mathrm{C}$ and shaked occasionally in a $15 \mathrm{ml}$ centrifuge tube (Corning), the suspension was filtered by $45 \mu \mathrm{m}$ cell strainer to remove large fragments and the collected liquid was centrifuged consecutively at $1500 \mathrm{rpm}, 1000 \mathrm{rpm}, 800 \mathrm{rpm}$ and $600 \mathrm{rpm}$ for $5 \mathrm{~min}$, respectively. Cancer cells were resuspended using primary culture medium (DMEM/ $\mathrm{F} 12+10 \% \mathrm{FBS}+1 \%$ penicillin-streptomycin $+0.2 \mathrm{U} / \mathrm{ml}$ insulin) and transferred to a tissue-culture flask overnight in a humidified incubator at $37{ }^{\circ} \mathrm{C}$ with $5 \% \mathrm{CO}_{2}$. Fresh medium can be changed every day.

In the first 3 months, fibroblast cells grew fast. During this time, some tumor cell "island" emerged. We removed the fibroblast scratching by pipetting tips and the tumor cell "island" became bigger. Tumor cell clones were picked out from the primary culture and purified, at passage 40 (13 months after we picked out the tumor cell clone), a stable cell line (HCS1220) was considered to have been established.

\section{Morphological of HCS1220}

HCS1220 were seeded in $25-\mathrm{mm}^{3}$ tissue-culture flasks and incubated at $37{ }^{\circ} \mathrm{C}$ in a humidified atmosphere containing $5 \% \mathrm{CO}_{2}$ for 2 weeks. Everyday the cells were placed under the inverted microscope to observe the general morphology.

\section{DNA isolation and STR (short tandem repeat) analysis}

Genomic DNA from HCS1220 was isolated using genomic extraction kit (Axygen, USA). The cell DNA was amplified by a 20-STR amplification method. STR loci and the sex gene Amelogenin were tested by an ABI 3730XL Genetic Analyzer. The data were analyzed by GeneScan and GeneMapperTM ID Software (Invitrogen).

\section{Karyotype analysis}

We performed chromosomal analysis on HCS1220 cells with low and high passages to determine whether chromosomal abnormalities could be considered in vivo or in vitro phenomena. The cells in logarithmic growth phase were harvested by trypsinization and DMEM/F12 medium were added to stop the reaction. After centrifugation at $1000 \mathrm{rpm}$ for $4 \mathrm{~min}, 0.56 \% \mathrm{KCl}$ solution $\left(37^{\circ} \mathrm{C}\right)$ was added and the hypotonic treatment was performed for $30 \mathrm{~min}$. Then the fixative (methanol/acetic acid 3:1) was added to fix the cells twice at room temperature for 30 min. Slides were air-dried and stained with Giemsa stain for $20 \mathrm{~min}$.

\section{Transplantation}

HCS1220 cells were digested with $0.25 \%$ trypsin and then counted. After centrifugation at $950 \mathrm{rpm}$ for $3 \mathrm{~min}$, the supernatant was discarded. The cells were resuspend in PBS to prepare a cell suspension of $1 \times 10^{6} \mathrm{cells} / \mathrm{ml}$.

Four 6-week-old BALB/c nude mice (Slac Laboratory Animal Company. Ltd, Shanghai) were subcutaneous injected $0.1 \mathrm{ml}$ suspension into the groin and the tumor formation was observed from the 7 th day. The mice were sacrificed when tumor burden exceed $10 \%$ of the normal body weight. The viable tumor tissues were fixed in $4 \%$ formaldehyde, paraffin embedded and diagnosed (H\&E staining).

\section{Detection of biomarkers for xenografts}

The expression of biomarkers CK20 and CDX2 for colon cancer and biomarkers AFP, hep-1 and glypican-3 for liver cancer were determined by immunocytochemistry assay. After deparaffinization and antigen retrieval procedure, slides were permeabilized with 
$0.1 \%$ Triton $\mathrm{X}-100$, incubated $5-10 \mathrm{~min}$ at room temperature with $0.3 \% \mathrm{H}_{2} \mathrm{O}_{2}$ solution and washed with distilled water and soak in PBS twice. Then blocked with 5-10\% goat serum (Invitrogen, USA) in PBS at room temperature, after $10 \mathrm{~min}$, The slides were incubated with the following primary antibodies at room temperature overnight: anti-CK20, anti-CDX2, anti-AFP, antihep-1 and anti-glypican-3. The secondary antibodies were supplied at $37^{\circ} \mathrm{C}$ for $10-30 \mathrm{~min}$. Next horseradish enzyme or alkaline phosphatase labeled streptavidin working solution could be added to incubate at $37^{\circ} \mathrm{C}$ for $10-30 \mathrm{~min}$. Finally, the hematoxylin was used in counterstaining.

\section{Detection of mycoplasma contamination}

Myco-PCR-Mix mycophenolate mycoplasma detection kit (Qiao Xinzhou Bioengineering Co. Ltd.) was used to detect mycoplasma contamination.

\section{Results}

\section{HCS1220 cell morphology}

The HCS1220 cells were obviously apytia with poorly differentiated morphology (Fig. 1). Cells disorderly grew and most of them appeared irregular polygon; Nucleus were larger than normal cells. When these nonadherent cells grew over the whole plate, they would be in overlap and pile up in high density, the results showed the cells had lost touching inhibition and had become malignant cells gradually.

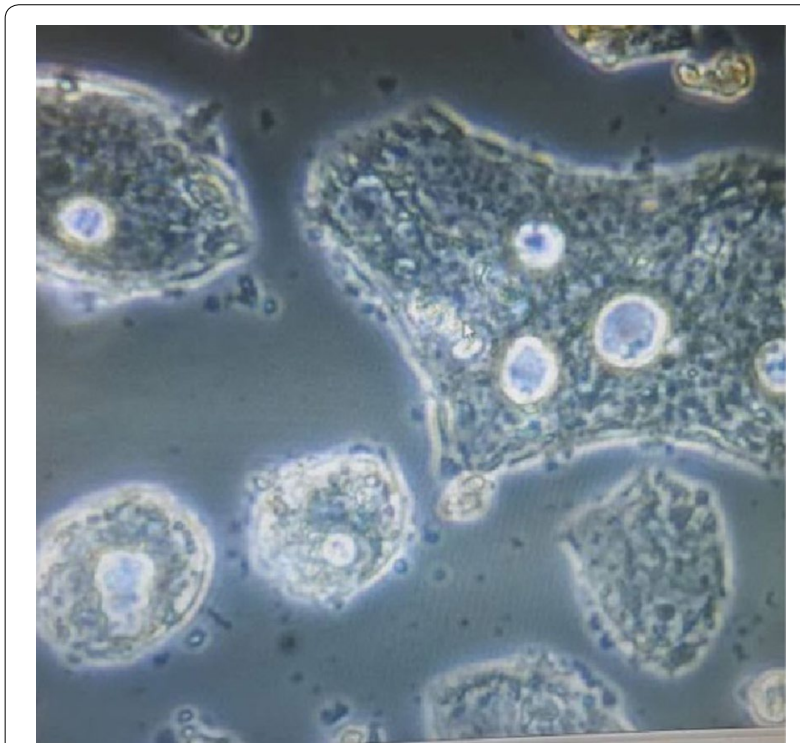

Fig. 1 Morphological image of the HCS1220 cells ( $\times 400$, final magnification)

\section{Analysis of short tandem repeats (STR)}

No matched cell lines were found in ATCC, DSMZ, JCRB and RIKEN cell bank and no multiple alleles were detected in the cell line. Test results shown in Table 1.

\section{Chromosome analysis}

The number of chromosomes was distributed in a range of 43-65 with a modal number of 45 (Fig. 2). HCS1220 cells were derived from human female aneuploid cells. The number and structure of chromosomes in the analyzed karyotype cells which abnormal were marked. Malignant proliferation of cells can be characterized as acceleration of nuclear fission, losing of nuclear fragmentation balance, uncontrolling cell proliferation and a substantial increase in gene copy number.

\section{Mycoplasma contamination}

As shown in Fig. 3, the stripe of internal standard control and positive control can be seen at $191 \mathrm{bp}, 278 \mathrm{bp}$, separately. There was only one stripe of the sample at $191 \mathrm{bp}$, the result showed there was no mycoplasma contamination in HCS1220.

Table 1 DNA fingerprinting analysis using STR loci for newly established HCS1220 cell lines

\begin{tabular}{|c|c|c|c|c|}
\hline \multirow[t]{3}{*}{ Loci } & \multirow{2}{*}{\multicolumn{2}{|c|}{$\begin{array}{l}\text { Cells to be detected } \\
\text { Cells' name: } 1220-1 \text { A P18 }\end{array}$}} & \multirow{2}{*}{\multicolumn{2}{|c|}{$\begin{array}{l}\text { Cells of the cell bank } \\
\text { Control cells' name: } \\
1220-1\end{array}$}} \\
\hline & & & & \\
\hline & Allele1 & Allele2 & Allele1 & Allele2 \\
\hline D5S818 & 10 & 12 & 10 & 12 \\
\hline D13S317 & 9 & 9 & 9 & 9 \\
\hline D7S820 & 11 & 12 & 11 & 12 \\
\hline D16S539 & 9 & 10 & 9 & 10 \\
\hline VWA & 17 & 17 & 17 & 17 \\
\hline TH01 & 9 & 10 & 9 & 10 \\
\hline AMEL & $x$ & $x$ & $x$ & $x$ \\
\hline TPOX & 8 & 8 & 8 & 8 \\
\hline CSF1PO & 11 & 12 & 11 & 12 \\
\hline D12S391 & 19 & 19 & 19 & 19 \\
\hline FGA & 25 & 25 & 25 & 25 \\
\hline D2S1338 & 18 & 23 & 18 & 23 \\
\hline D21S11 & 29 & 29 & 29 & 29 \\
\hline D18S51 & 17 & 17 & 17 & 17 \\
\hline D8S1179 & 13 & 15 & 13 & 15 \\
\hline D3S1358 & 15 & 15 & 15 & 17 \\
\hline D6S1043 & 12 & 19 & 12 & 19 \\
\hline PENTAE & 16 & 17 & 16 & 17 \\
\hline D19S433 & 15.2 & 16.2 & 15.2 & 16.2 \\
\hline PENTAD & 11 & 11 & 11 & 11 \\
\hline
\end{tabular}




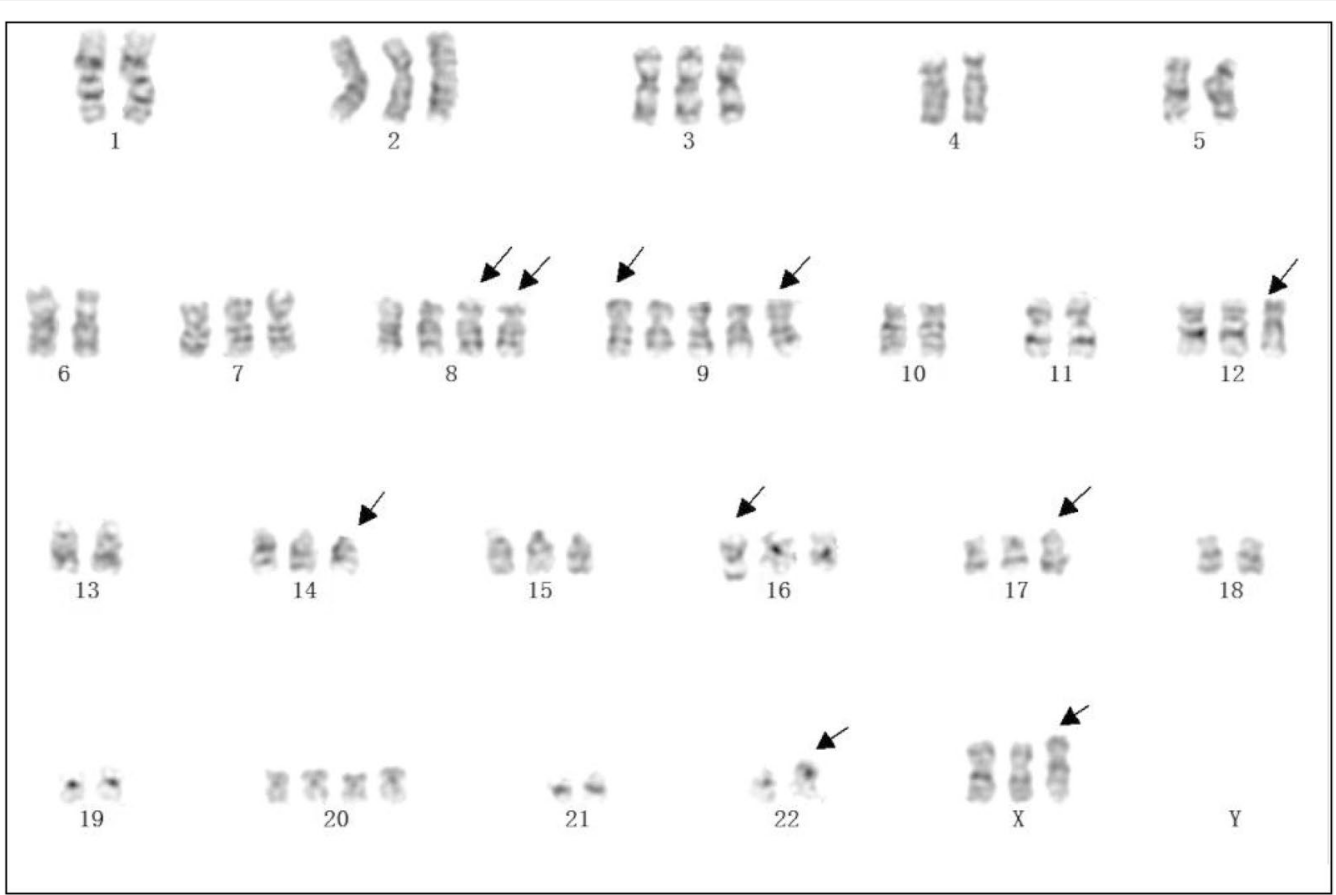

Fig. 2 Representative karyotype of HCS1220 cells

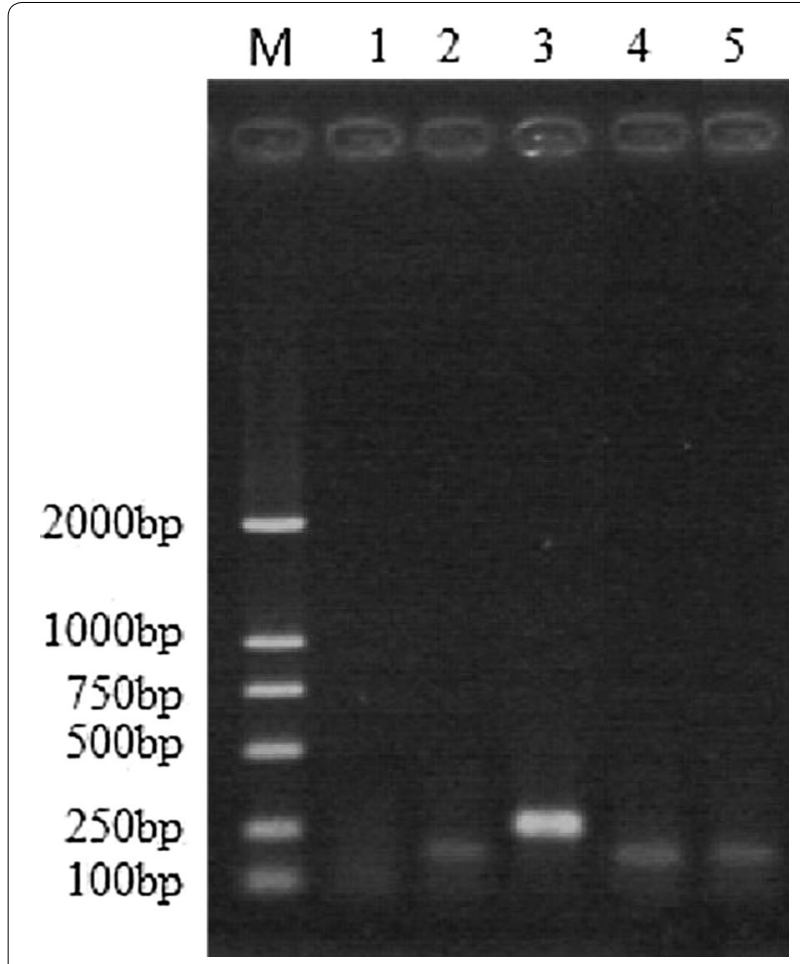

Fig. 3 The electrophoretic analysis of mycoplasma contamination M: DNA Marke; Line 1: Negative control; Line 2: Internal Control; Line 3: Positive Control; Line 4 and Line 5: HCS1220

\section{Xenograft model}

Xenograft model was established to confirm the effect of HCS1220 cell on tumor formation in animal. After 3 weeks, all of $4 \mathrm{BALB} / \mathrm{c}$ nude mice which subcutaneous injected $1 \times 10^{6} \mathrm{HCS} 1220$ cells have formed tumor at the injected sites and some tumors infiltrated the muscle layer, indicating that HCS1220 cells could inform tumor in animal model. Sacrificing the mice and peeling off the tumor, as shown in Fig. 4a, the solid tumor was clearly observed for blood supply and encapsulated. Histopathological results could be seen obviously, such as heterotypic cells type, large and deep staining nuclei and a large proportion of nuclear plasma, what's more, cells were surrounded by interstitial cells, which formed a large number of duct-like structure (Fig. 4b), the same as the histopathological results of patient's resected tumor (Fig. 4c). Those were all clinically and pathologically diagnosed as mucinous adenocarcinoma, which was consistent with the pathological features of colon cancer.

\section{Detection of tumor biomarkers}

The results of immunohistochemical staining for some biomarkers of xenograft tumor were shown in Fig. 5. AFP, hep- 1 and glypican-3, the well-used biomarkers for HCC, were negative and two well-known tumor markers for colon cancer, CK20, CDX2 were positive, clearly indicating that xenograft tumor were derived from intestinal tissue. 

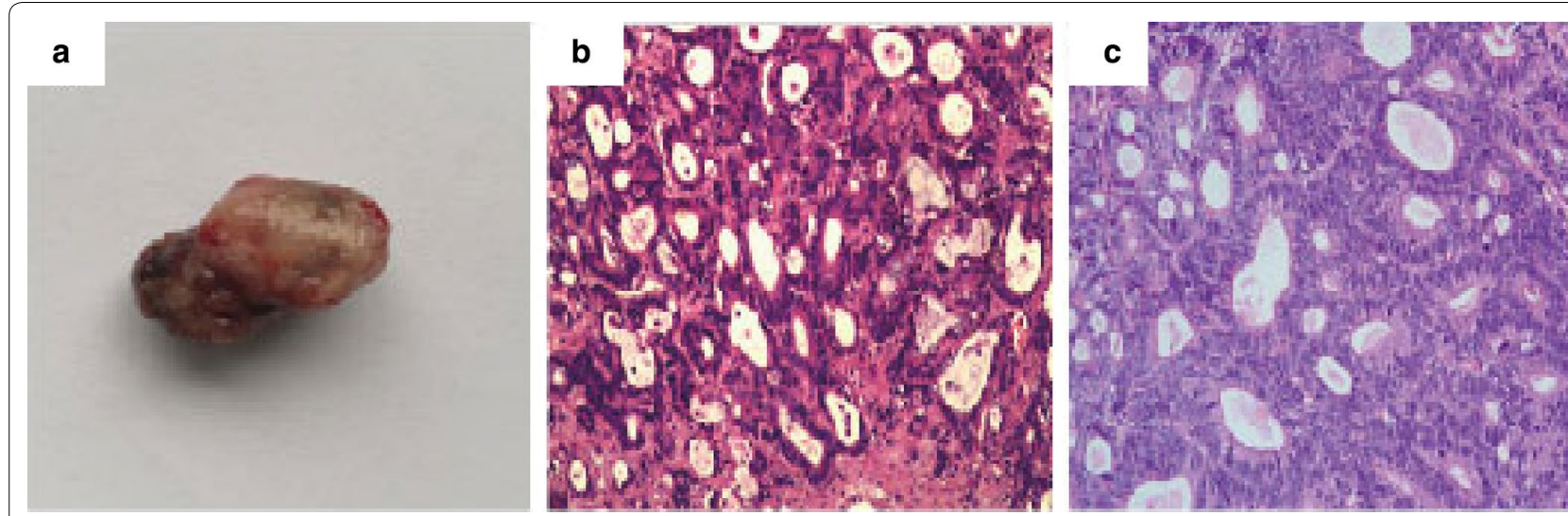

Fig. 4 Nude mouse tumorigenicity assay. $1 \times 10^{6} \mathrm{HCS} 1220$ cells were subcutaneously injected into the groin of immunodeficient nude mice, after 3 weeks, $\mathbf{a}$ the solid tumor was obtained. $\mathbf{b}$ Histological analysis of Clinical tumor specimens and $\mathbf{c}$ xenografts tumors of nude mice. Sections were stained with haematoxylin and eosin (H\&E). Magnification, $\times 200$
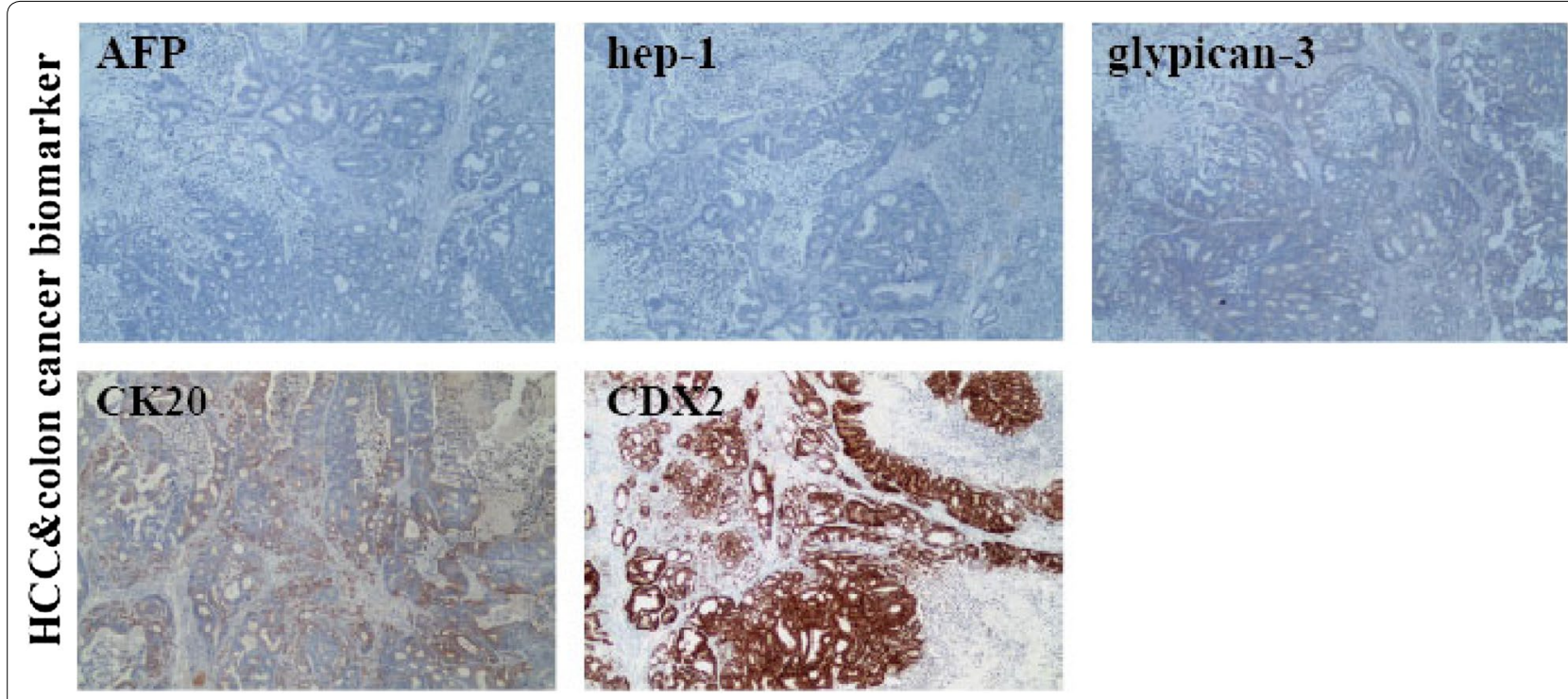

Fig. 5 Immunohistochemical stain of the HCS1220 cells. 5 tumor related biomarkers were visualized by special antibodies including colon cancer markers CK20, CDX2 and hepatocellular carcinoma markers AFP, hep-1, glypican-3. Magnification, $\times 40$

\section{Discussion}

Most malignant cancers in the liver are not primary but metastasis of cancer from elsewhere in the body, e.g. the colon. However, there are only about 10 human liver metastatic of colon cancer cell lines existing in ATCC, DSMZ, JCRB and RIKEN databases. Establishing sufficient hepatic metastasis of colon cancer cell line is now important to research the mechanism of tumor metastasis, carcinoma growth microenvironment, antitumor drugs' sensitivity influence and the tumor drug resistance.

We have established and characterized a stably growing cell line from a liver metastasis of colon cancer patient which named HCS1220. The cell line cultured in vitro for more than 7 months, at high magnification, HCS1220 has the characteristics of rapid and stable growth, continuous passage, the contact loss during the growth process which could be defined as proliferation of malignant tumor. Chromosome analysis revealed the cells derived from human female. The cells are highly aneuploidy, the number and structure of chromosomes was abnormal. Accelerated nuclear fission, losing the balance of nuclear fragmentation, uncontrolled cell proliferation, a substantial increase in gene copy number, which are signs of polyploid cells, chromosomal abnormalities may be associated with 
the characteristics of independent of cell growth, the advantages of proliferation and tumorigenicity of the immunocompromised mice.

Cell line identification is strict during development to avoid the risks of using misidentified cells [7]. Recent studies have shown that more than 360 cell lines were cross-contaminated or misidentified without authenticated stock, and the validity of the studies using these cell lines were in doubt [8]. A cell line is considered misidentified when its DNA profile is not consistent with the individual from whom it was derived from. Here, we analyzed that the STR profiles which confirmed that no matched cell lines in 2455 cell line STR data from ATCC, DSMZ, JCRB and RIKEN databases, which means the HCS1220 cell line was first established in the databases. The results also demonstrated the cells were malignant tumor origin [9]. To confirm the origin of the cells, we injecting the cells to establish the implantation model in vitro, the results showed the subcutaneous xenografts of HCS1220 in nude mice were easily informed and presented as expanding outgrowths with strong invasion.

As the tumor resected from the liver, so we explored whether the HCS1220 cell line originated from metastasis of colon cancer or primary liver cancer. From the results of biomarkers assay, we found that no matter the HCS1220 cell or implantation tumor tissue, they all expressed the colon cancer biomarker CK20, CDX2, a-fetoprotein, hep-1, glypican-3 stained negative, the results demonstrated that the HCS1220 cell line originating from the intestinal tissue.

\section{Conclusion}

In summary, HCS1220 cell line has the characteristics of primary human liver metastasis of colon cancer and it is consistent with the established lineage standard. The results of STR has genetically showed that established human tumor cell line from liver metastasis of colon cancer is original, which can provided cell materials for research in vitro in the pathogenesis of liver metastasis and individualized treatment. What's more, it can also help to provide the foundation for establishing the mechanism model of liver metastasis of colon cancer and preparing, screening and evaluating anti-tumor drugs.

\footnotetext{
Abbreviations

STR: short tandem repeat; CK20: cytokeratin; CDX2: caudal type homeobox transcription factor 2; AFP: a-fetoprotein; CEA: carcinoembryonic antigen; CA199: carbohydrate antigen 199; HEP-1: heparinase; CA724: carbohydrate antigen 724; NSE: 2-phospho-D-glycerate hydrolase; MRI: nuclear magnetic resonance imaging; DMEM: Dulbecco's modified eagle medium; DMEM/ F12: Dulbecco's Modified Eagle Media: Nutrient Mixture F-12; PBS: phosphate buffer saline; FBS: fetal bovine serum; PCR: polymerase chain reaction; H\&E: haematoxylin and eosin; DNA: deoxyribonucleic acid.
}

Authors' contributions

FZ and YC designed the study. HW extracted, analyzed, and interpreted the data and wrote the manuscript. All authors read and approved the final manuscript.

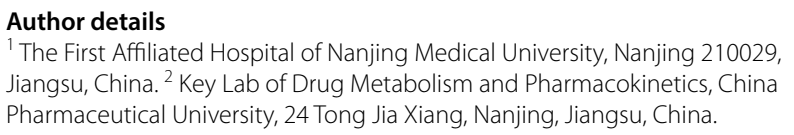

\section{Acknowledgements}

The authors are grateful to all staff at the study centre who contributed to this study.

\section{Competing interests}

The authors declare that they have no competing interests.

\section{Availability of data and materials}

All data generated or analysed during this study are included in this published article.

\section{Consent for publication}

If your manuscript does not contain data from any individual person, please state "Not applicable" in this section.

\section{Ethics approval and consent to participate}

This study was approved by the Ethics Review Board of the First Affiliated Hospital of Nanjing Medical University (Nanjing, China). All experiments were performed according to relevant guidelines; informed consent was obtained from each patient. All animal experimental protocols were approved by the Animal Research Ethics Committee of the First Affiliated Hospital of Nanjing Medical University and complied with the rules of the specific pathogen-free (SPF) animal laboratory of the Nanjing Medical University.

\section{Funding}

This work was financially supported by grants from the Six talent peaks project in Jiangsu Province of china [WSN-088(IB16)], the key young talents of medicine in Jiangsu Province (QNRC2016591), the National Natural Science Foundation of China $(81472809,81502653,81672983,81703028)$, the Priority Academic Program Development of Jiangsu Higher Education Institutions (PAPD) (JX10231801), NCI Mouse Models Consortium (UO1CA141545).

\section{Publisher's Note}

Springer Nature remains neutral with regard to jurisdictional claims in published maps and institutional affiliations.

Received: 29 June 2018 Accepted: 31 August 2018

Published online: 10 September 2018

\section{References}

1. Chen $\mathrm{H}, \mathrm{Xu} \mathrm{L}$, Yin L, et al. iTRAQ -based proteomic analysis of dioscin on human HCT-116 colon cancer cells. Proteomics. 2014;14:51-73.

2. Sullivan WJ, Christofk HR. The metabolic milieu of metastases. Cell. 2015;160(3):363-4.

3. Loo JM, Scherl A, Nguyen A, et al. Extracellular metabolic energetics can promote cancer progression. Cell. 2015;160(3):393-406.

4. Lee YS, Lee DG, Lee JY, et al. A formulated red ginseng extract upregulates CHOP and increases TRAIL-mediated cytotoxicity in human hepatocellular carcinoma cells. Int J of Oncol. 2013;43(2):591-9.

5. Barallon R, Bauer SR, Butler J, et al. Recommendation of short tandem repeat profiling for authenticating human cell lines, stem cells, and tissues. Vitro Cell Dev Bio Anim. 2010;46(9):727-32.

6. Workgroup ATCCSDO. Cell line misidentification: the beginning of the end. Nat Rev Cancer. 2010;10(6):441-8.

7. Cheung PF, Yip CW, Ng LW, et al. Establishment and characterization of a novel primary hepatocellular carcinoma cell line with metastatic ability in vivo. Cancer Cell Int. 2014;14(1):103. 
8. Capes-Davis A, Theodosopoulos G, Atkin I, et al. Check your cultures! A list of cross-contaminated or misidentified cell lines. Int J Cancer. 2010;127(1):1-8.
9. Qiu Z, Zou K, Zhuang L, et al. Hepatocellular carcinoma cell lines retain the genomic and transcriptomic landscapes of primary human cancers. Sci Rep. 2016;6:27411.
Ready to submit your research? Choose BMC and benefit from:

- fast, convenient online submission

- thorough peer review by experienced researchers in your field

- rapid publication on acceptance

- support for research data, including large and complex data types

- gold Open Access which fosters wider collaboration and increased citations

- maximum visibility for your research: over $100 \mathrm{M}$ website views per year

At BMC, research is always in progress.

Learn more biomedcentral.com/submissions 